\title{
THE OUTCOME OF LIMITED URETHRAL MOBILIZATION URETHROPLASTY FOR ANTERIOR HYPOSPADIAS.
}

1. MBBS, FCPS

Assistant Professor Paeds Surgery Sahiwal Medical College Sahiwal.

2. MBBS, FCPS

Senior Registrar Paeds Surgery Sahiwal Medical College Sahiwal.

3. MBBS

WMO

Basic Health Unit Dhakranwall Kharian.

4. MBBS

Post Graduate Trainee

SIMS / Services Hospital Lahore.

5. MBBS, M.Phil

Assistant Professor

Physiology Department

Sahiwal Medical College Sahiwal.

6. MBBS, FCPS

Senior Registrar General Surgery

Sahiwal Medical College Sahiwal.

Correspondence Address:

Dr. Shafiq-ur-Rehman

Head of Pediatric Surgery

Sahiwal Medical College Sahiwal.

Article received on:

19/08/2019

Accepted for publication:

$25 / 11 / 2019$

\section{Shafiq-ur-Rehman', Yasir Makki², Fareena Ishtiaq ${ }^{3}$, Waleeja Shamikha ${ }^{4}$, Nauman Aziz ${ }^{5}$, Saad Fazal ${ }^{6}$}

ABSTRACT... Objectives: Hypospadias, one of the most common genital anomalies, is characterized by an abnormal meatal opening on the ventral aspect of penis. Anterior hypospadias are the most common. Most of the surgical techniques involves the construction of neourethra with significant risk of urethrocutaneous fistula. Limited urethral mobilization technique involves the advancement of native urethra. Study Design: The objective of this study was to evaluate the outcome of Limited Urethral Mobilization Urethroplasty for Anterior Hypospadias. Setting: The study was conducted in the Department of Paediatric Surgery, DHQ teaching Hospital Sahiwal. Period: From January 2016 to December 2018. Material \& Methods: A total number of 187 patients were included in this study. Limited urethral mobilization technique was used in all patients. Minimum age was 2.5 Years and maximum age was 12 years. Cosmetic appearance, functional outcome and complication rate were assessed. Results: Wound infection developed in $3.20 \%(n=6)$ patients. Complete glanular disruption was seen in $2.13 \%(n=4)$ patients. Partial disruption of glans with meatal retraction was observed in $1.60 \%(n=3)$ patients. Postoperative haematoma was seen in $1.60 \%(n=3)$ patients. Meatal stenosis in $1.06 \%(n=2)$ patients. Post-operative bleeding and diverticula was observed in $0.5 \%(n=1)$ patients each. Vertical oriented, slit like meatus at the tip of glans was achieved in $95.72 \%(n=179)$ patients. Conclusion: Limited urethral mobilization urethroplasty is a technique with proven benefits and effectiveness in the terms of cosmesis and functional outcome with a minimal number of complications because of the usage of native elastic urethra.

Key words: $\quad$ Anterior Hypospadias, Beck Urethroplasty, Limited Urethral Mobilization, Meatal Mobilization Urethroplasty, Outcome.

Article Citation: Shafiq-ur-Rehman, Makki Y, Ishtiaq F, Shamikha W, Aziz N, Fazal S. The outcome of limited urethral mobilization urethroplasty for anterior hypospadias. Professional Med J 2020; 27(1):210-216.

DOI: 10.29309/TPMJ/2020.27.1.4055

\section{INTRODUCTION}

The incidence of hypospadias is 1:125 live male births. ${ }^{1,2}$ It is increasing worldwide. Hypospadias is a developmental disorder in which the opening of the urethra is in an abnormal location. It may be at the ventral aspect of the penile shaft, on the scrotum or even in the perineum. It is a developmental arrest of urethral foreskin and the ventral aspect of penis. ${ }^{3}$

Majority of cases of hypospadias are of distal variety, with an incidence of $75 \% .{ }^{4}$ Majority of patients with distal hypospadias have no chordee or minimal chordee. These children are able to void with straight stream. However, most parents wish for a normal penis for their children. Therefore operative reconstruction is recommended for all children in this group for cosmetic requirements and also for psychosocial reasons.

Surgical reconstruction is the only treatment option for hypospadias. ${ }^{3}$ Hypospadias surgery is challenging. Surgeons are still in search of an ideal technique. A large variety of surgical techniques has been described and is currently in use. More than 300 procedures have been mentioned in the literature. ${ }^{5}$ The overall results of surgical management of hypospadias are still beyond the satisfaction with high incidence of complications and redo surgeries. The ultimate success of the operation is determined by normal appearing penis, slit like vertical oriented meatus at the tip of glans, normal voiding with straight forward direction, minimal complication rate and 
short hospital stay.

Different techniques are available to repair distal hypospadias. Instead of creating new, advancement of native urethra for hypospadias repair, is very old concept and was first introduced in 1898 by Beck. ${ }^{6}$ The technique of urethroplasty based on the concept of Beck was not consistently successful. It was due to inadequate mobilization of urethra. With the passage of time, Beck procedure was improved and revived by Koff et al $1994^{7}$ and Anthony Atala. ${ }^{8}$ So the concept of urethral mobilization and advancement is very old and being widely incorporated in different techniques for hypospadias repair. Limited urethral mobilization (LUM) urethroplasty and meatal mobilization (MEMO) urethroplasty, are techniques which have been developed on concept introduced by Beck. Now a days, these techniques are again getting popularity and position in the management of hypospadias. We designed our study to evaluate the outcome of Limited Urethral Mobilization Urethroplasty for Anterior Hypospadias.

\section{MATERIAL AND METHODS}

The study was conducted in the Department of Pediatric Surgery of DHQ Teaching Hospital Sahiwal, from January 2016 to December 2018. A total of 187 patients of anterior hypospadias were included, who were admitted via outpatient department.

\section{Inclusion Criteria}

1. The patients with glanular, coronal, sub coronal and distal penile hypospadias.

2. The patients with previous history of hypospadias surgery.

3. The patients with mild chordee and torsion.

4. The patients already circumcised.

\section{Exclusion Criteria}

1. The patients with severe chordee.

2. The patients with severe comorbidities.

In 22 children, meatus was glanular in position, 87 patients were having coronal hypospadias, 40 patients were of sub coronal variety and 38 patients of distal penile hypospadias were included. Thirteen patients had mild chordee and nine patients with penile torsion were included in this study. Thirty three were already circumcised. Eleven patients had previous surgery for hypospadias. Five patients were operated in our department whereas six patients were referred from outside for redo urethroplasty. The age of the patients included in this study was from 2.5 years to 12 years. Permission from ethical review committee, Sahiwal Medical College, Sahiwal, was obtained. All the parents/ guardians were briefed about the procedure and the complications. Informed detailed consent was taken for all the patients from their guardians/ Parents. Preoperative evaluation of every patient was done.

After induction of general anesthesia, antiseptic wash and aseptic draping, the distance between the tip of the glans and meatal opening was measured and noted. A traction suture was applied at the tip of the glans with $5 / 0$ vicryl. Incision lines were marked with a sterile marker. Depending upon the age of the patients, a feeding tube of approximately 6-8 Fr was passed in the meatal opening. Meatus was circumferentially incised along with mobilization of distal urethra, extending proximally. By doing this, sufficient length was achieved to allow urethra to reach the glans tip. In some cases, thin urethra was seen. That thin portion was excised in tangential fashion. Length of the mobilized urethra was measured and recorded.

Circumcising incision was made and penile skin was degloved. Glans wings were mobilized and prepared by excising excess tissue. Glanular bed was prepared to receive mobilized urethra. Dorsal lip was sutured to the glanular tip with polygalactane $5 / 0$ in interrupted fashion. Glans wings were closed over newly placed urethra with interrupted sutures. Circumcision was performed in all cases. In patients with mild chordee and torsion, penile skin was degloved down to penoscrotal junction to relieve the skin chordee and torsion. Dorsal plication was performed in selected cases. Penile tourniquet was used in all cases and was removed after glans reconstruction. Stent was secured with a 
stitch which was previously placed on glans for traction. Compression dressing was done.

Intravenous co amoxi clav was started and given throughout. Oxybutynin was used selectively at the rate of $0.2 \mathrm{mg} / \mathrm{kg}$. Intravenous paracetamol and oral ibuprofen was used as analgesic. Stent was removed on $7^{\text {th }}$ post-operative day and patient allowed to void spontaneously and discharged on the same day. Patient was asked to visit again at $15^{\text {th }}$ post op day, one month, three months $\mathrm{s}$ and six months. Minimum follow up for all the patients was 6 months each. The parameter used to evaluate the cosmetic appearance of penis, was slit like meatus at the tip of conical glans without residual chordee and torsion. Functional outcome was evaluated with good straight forward directed stream of the urine from the tip of the glans. Complications e.g. bleeding, hematoma, infection, partial or complete glanular disruption, stenosis, urethrocutaneous fistula, diverticula and stricture formation were noted over the course of time.

\section{Statistical Analysis}

Statistical analysis was performed using SPSS. Quantitative data was shown as mean \pm standard deviation. Student $t$ test was performed and bias was set at $p<0.05$ with confidence rate of $95 \%$.

\section{FIGURES}

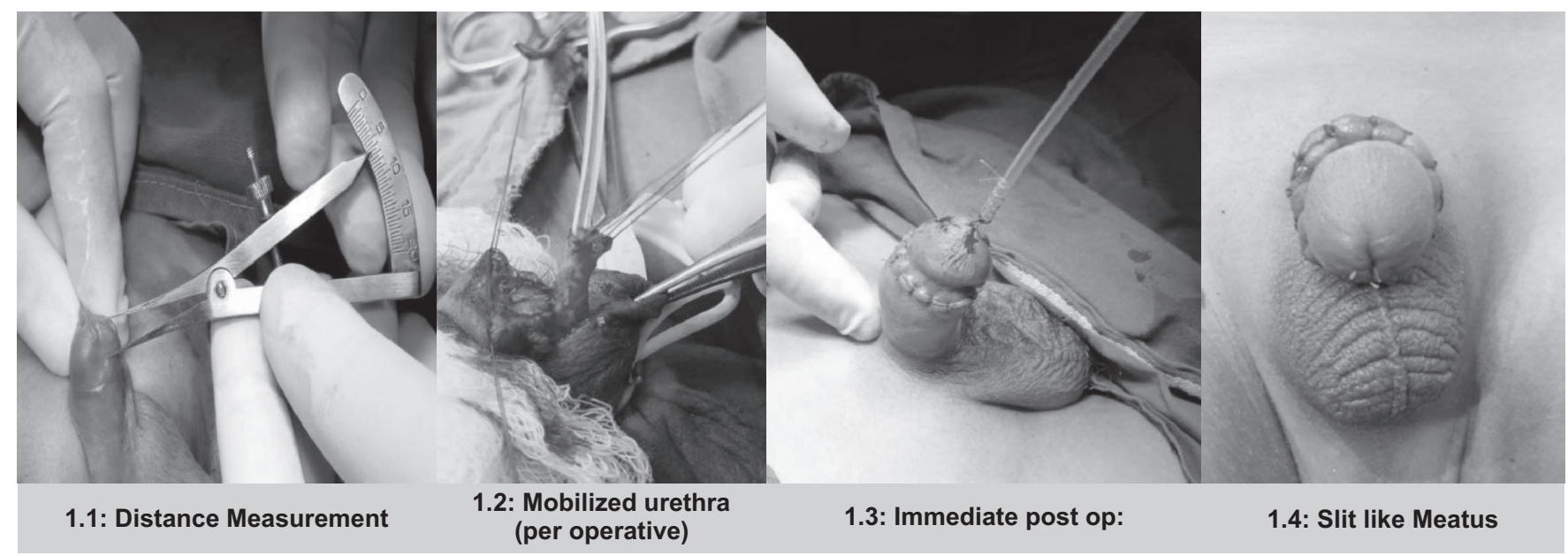




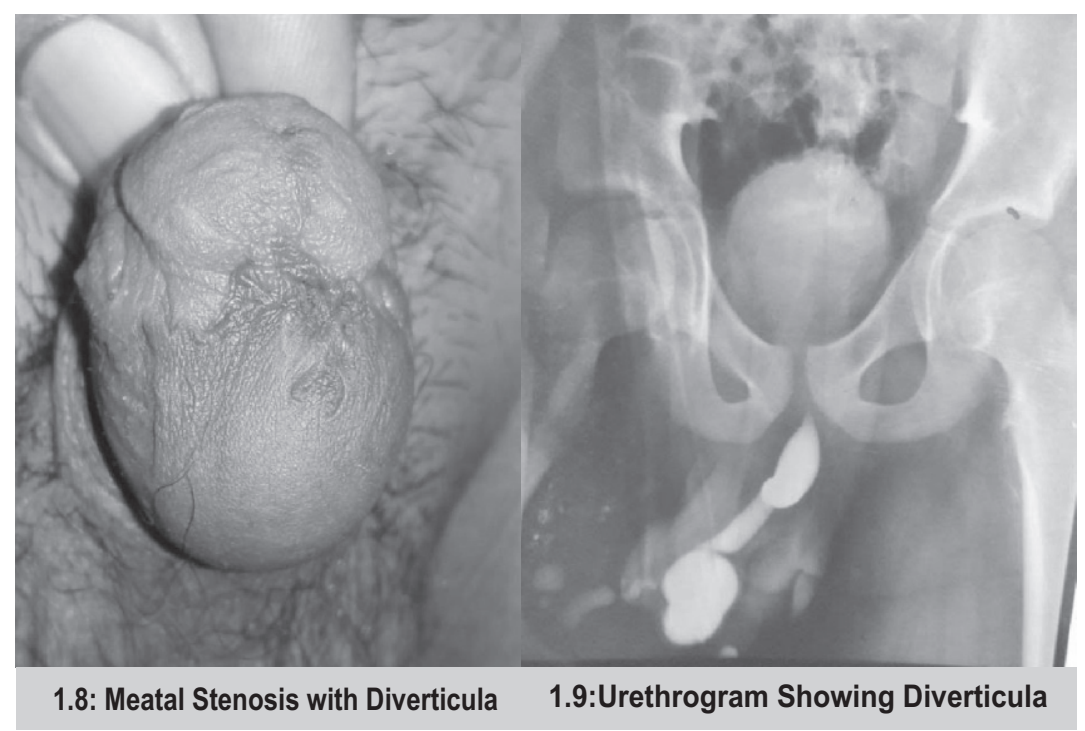

\section{RESULTS}

All 187 children included in this study underwent single stage, limited urethral mobilization urethroplasty. Follow up period ranged from 6 to 24 months (mean 10.9 months). The mean distance from the urethral meatus to the glans tip was $7.91 \mathrm{~mm}$ ( 4 to $13 \mathrm{~mm}$ ) and the mean length of mobilized urethra was $15.35 \mathrm{~mm}$ (08 to $26 \mathrm{~mm}$ ). The ratio of the length of the mobilized urethra to the distance of ectopic meatus from the tip of glans was $1.94(1.55$ to 2.50$)$. Mean operation time was 61.32 minutes ( $48-87$ minutes). The mean duration of hospitalization was 3.41 days ( 3 to 9 days).

Most common complication was wound infection, which developed in 6 patients (3.20\%). Complete glanular disruption was seen in 4patients (2.13\%). Redo urethroplasty was done in all patients with complete glanular disruption. Partial disruption of glans with meatal retraction developed in 3 patients (1.60\%). Out of these three patients with partial glanular disruption, one patient developed meatal stenosis. The same patient was initially managed with urethral dilatation, but latter on redo urethroplasty was performed. Three patients (1.06\%) developed post-operative hematoma. Meatal stenosis was observed in two patients (1.06\%). Urethral diverticulum was observed in one patient $(0.53 \%)$. Immediate post-operative bleeding occured in one patient $(0.53 \%)$, which has to be secured under general anesthesia. No urethrocutaneous fistula, persistent chordee, residual torsion, urethral stricture and devitalized skin flap were observed during extended follow up. A very good cosmetic appearance and functional outcome was achieved in 179 patients (95.72\%).

\begin{tabular}{|l|c|c|}
\hline Types of Hypospadias & Numbers & Percent \\
\hline Glanular & 22 & $11.76 \%$ \\
\hline Coronal & 87 & $46.52 \%$ \\
\hline Sub coronal & 40 & $21.39 \%$ \\
\hline Distal penile hypospadias & 38 & $20.32 \%$ \\
\hline
\end{tabular}

Table-I. Types of hypospadias.

\begin{tabular}{|l|c|c|}
\hline & \multicolumn{1}{|c|}{ Range } & Mean Value \\
\hline Age. & 2.5year to 12 years & 4.8 years \\
\hline Operation Time & $4 \mathrm{~m}$ to13mm & $7.91 \mathrm{~mm}$ \\
\hline $\begin{array}{l}\text { Distance between } \\
\text { Meatus and Tip of Glans }\end{array}$ & $8 \mathrm{~mm}$ to $26 \mathrm{~mm}$ & $15.35 \mathrm{~mm}$ \\
\hline $\begin{array}{l}\text { Length of Mobilized } \\
\text { Urethra }\end{array}$ & 1.5 to .2 .50 & $1.94 \mathrm{~mm}$ \\
\hline $\begin{array}{l}\text { Length of Mobilized } \\
\text { Urethra / Distance between } \\
\text { Meatus and Tip of Glans }\end{array}$ & 06 to 24 months & 10.9 months \\
\hline Follow UP &
\end{tabular}

Table-II. Mean values of different variables.

\begin{tabular}{|l|c|c|}
\hline Post Op Complications & Number & Percent \\
\hline Wound Infection & 06 & $3.20 \%$ \\
\hline $\begin{array}{l}\text { Complete Glanular } \\
\text { Disruption }\end{array}$ & 04 & $2.13 \%$ \\
\hline $\begin{array}{l}\text { Partial glanular disruption } \\
\text { with Meatal retraction }\end{array}$ & 03 & $1.60 \%$ \\
\hline \begin{tabular}{l|l|} 
Haematoma \\
Meatal stenosis
\end{tabular} & 03 & $1.60 \%$ \\
\hline Bleeding & 02 & $1.06 \%$ \\
\hline Table-III. Complications. & $0.53 \%$ \\
\hline
\end{tabular}




\section{DISCUSSION}

A large number of surgical procedures are being practiced to repair distal hypospadias. ${ }^{1,9}$ Most commonly used techniques are tubularized incised plate urethroplasty (TIP), meatal advancement and glanuloplasty incorporation (MAGPI), Mathieu's flip flap procedure, and glans approximation procedure (GAP).

Tubularized incised plate urethroplasty, popularized by Snodgrass et al, ${ }^{10}$ is very popular among the surgeons dealing with hypospadias, ${ }^{11}$ has disadvantage of ventral suture line. This technique is also not suitable for patients with shallow urethral plate and small sized glans. Commonly reported complications with this technique are urethro cutaneous fistula and meatal stenosis. Snodgrass reported the incidence of urethro cutaneous fistula formation as $4 \%$ and meatal stenosis as 6.7\%. ${ }^{12}$ Shoeib MA (2015) reported complications of Snodgrass repair as overall complications $8.8 \%$, urethro cutaneous fistula $2.6 \%$ and wound infection $6.2 \% .^{13}$ As this technique involves the dorsal incision in the urethral plate, that might cause fibrosis of spongial tissue and stricture formation. ${ }^{14,15}$ To decrease the risk of urethrocutaneous fistula, a vascularized tissue flap is applied over the neo urethra as a second layer. ${ }^{16}$

The MAGPI technique is also commonly used for distal hypospadias, especially glanular and coronal types. This technique is reported for difficulty in correction of chordee, unsatisfactory cosmesis, meatal regression, meatal stenosis and rounded urethra with splaying of urinary stream. ${ }^{17,18,19,20}$

We used limited urethral mobilization urethroplasty in all 187 patients of distal hypospadias, with results comparable to other series. ${ }^{21}$ In some series, this technique and similar techniques like meatal mobilization (MEMO) is considered good option only in selected patients with appropriately mobile urethra and patients with densely fixed urethra were excluded. ${ }^{22,23,24}$ This technique is not very widely used, most probably due to the fear of devascularisation of mobilized urethra. This technique must not be discarded due to this fear.
Urethra is adequately supplied by urethral branch of internal pudendal artery and terminal branches of dorsal penile artery. ${ }^{25}$ If the urethral mobilization is meticulous, the fear of devascularisation seems to be unfounded. ${ }^{26,27}$ The continuous growth of native elastic, spongy urethra that keeps pace with general growth of the child is also the benefit of this technique. ${ }^{26,28}$

Similar to many other series, the patients with mild chordee, torsion, previously circumcised and previous unsuccessful surgery for hypospadias were included in our study. We used this technique in eleven patients with complete or partial glanular disruption and achieved very good cosmetic and function outcome. Elemen and Tugay used this technique for secondary reconstruction in nine patients with very good results. ${ }^{29}$

The mean operation time (61.32minutes) and mean hospital (3.41days) is similar to those as mentioned in literature. The mean distance between the ectopic meatus and the tip of glans is $7.91 \mathrm{~mm}(4-13 \mathrm{~mm})$ and the mean length of mobilized urethra to achieve tension free anastomosis is $15.35 \mathrm{~mm}(8-26 \mathrm{~mm})$. The mean ratio between the length of mobilized urethra and the distance between the meatus and tip of glans is 1.94(1.55-2.50). Almost same ratio (1.52.5) is reported by Gharieb M (22). Chakraborty AK 2017 reported that 2.7-3.2(3.1) fold urethral mobilization is adequate to secure anastomosis between urethra and glans and to preclude the chordee. ${ }^{30}$ In some series four to five fold mobilization of urethra is recommended to gain tension free anastomosis. ${ }^{31,32}$ This much urethral mobilization may be required in midshaft and proximal hypospadias, which were not included in our study. Our data showed that 1.94 (1.552.50) fold urethral mobilizations is sufficient for patients with distal hypospadias. In secondary reconstruction and patient with chordee require slightly more extensive mobilization. Hassan HS 2015, performed urethral mobilization to the proximal shaft in almost all cases of distal hypospadias with chordee. ${ }^{32}$ Extensive urethral mobilization may compromise the blood supply and lead to spongiosclerosis. Whereas the inadequate urethral mobilization may result in 
chordee. No residual chordee was seen in our patients. However adequate and meticulous urethral mobilization is key factor in the success of this technique.

Urethrocutaneous fistula is very problematic complication of all sorts of hypospadias repairs. Karim S, reported urethro cutaneous fistula in $1.47 \%$ patients with LUM urethroplasty and in $14.29 \%$ patients with modified Snodgrass repair. ${ }^{33}$ High incidence of urethro cutaneous fistula with tubularized incised plate urethroplasty has been reported in many studies. ${ }^{20,29,34,35}$ No uerthro cutaneous fistula noted in our study.

Meatal stenosis is very commonly reported complication and considered main drawback of this technique. ${ }^{36}$ Hassan HS 2015, report meatal stenosis in $10 \%(n=3)$ patients. ${ }^{32}$ In our study, $1.06 \%(n=2)$ patients developed meatal stenosis. However, one patient with meatal stenosis also developed urethral diverticula. It is a rarely reported complication in LUM urethroplasty. This patient lost to follow up and reported after three months with meatal stenosis and diverticula.

\section{CONCLUSION}

The limited urethral mobilization urethroplasty is a technique with proven benefits and effectiveness in terms of cosmesis, functional outcome and complication rate. It is useful in all patients of distal hypospadias including distal penile shaft variety. It is also useful in patients with torsion, mild chordee, previously circumcised and the patients requiring redo urethroplasty. About two fold urethral mobilization is sufficient in most of the patients of distal hypospadias.

\section{Copyright@ 25 Nov, 2019.}

\section{REFERENCES}

1. Paulozzi L, Erickson D, Jackson. Hypospadias trends in two US surveillance systems. Pediatrics 1997; 100:831-834.

2. Paulozzi, LJ. International trends in rates of hypospadias and cryptorchidism. Environ Health perspect 1999; 107:297-302.

3. Baskin LS, Ebbers MB. Hypospadias anatomy, etiology, and technique. J pediatr Surg 2006; 41:463472
4. Alkan M, Oguzkurt P, Ezer SS, Ince Hicsonmez A: Evaluation of the results of eccentric circummeatalbased flap with combined limited urethral mobilization technique for distal hypospadias repair J Pediatr Urol. 2008; 4:206-209

5. Hamdy $\mathrm{H}$, Awadhi MA, Rasromani $\mathrm{KH}$. Urethral mobilization and meatal advancement: A surgical principal in hypospadias repair. Pediatr Surg Int 1999; $15: 240-2$

6. Beck C: A new operation for balanic hypospadias. NY Med J. 1898; 67: 147.

7. Beck C: Hypospadias and its treatment. Surg Gynecol Obstet 1917; 24:511-532.

8. Koff SA, Brinkman J, Ulrich J, \& Deighton D. Extensive mobilization of urethral plate and urethra for repair of hypospadias: The modified Barcat Technique. J Urol 2002; Oct; 168:1738-41; discussion 1741.

9. Yesildag E, Tekant $G$, Sarimurat $N$, Buyukunal SN. Do patch procedure prevent complications of the Mathieu technique? J Urol. 2004; 171:2623-5.

10. W. Snodgrass, M. Koyle, G. Manzoni, R. Hurwitz, A. Caldamonoyle, and R. Ehrlich, "Tubularized incised plate hypospadias repair for proximal hypospadias," The Journal of Urology, vol. 159, no. 6 pp. 2129-2131, 1998.

11. W. Snodgrass, M. Koyle, G. Manzoni, R. Hurwitz, A. Caldamone, and R. Ehrlich, "Tubularized incised plate hypospadias repair: Results of a multicenter experience," The Journal of urology, vol. 156, no. 2 supplement 1, pp. 839-841,1996.

12. Snodgrass WT. Tubularized incised plate hypospadias repair: Indications, technique and complications. Urology 1999; 54: 6-11.

13. Shoeib MA. Snodgrass repair of hypospadias (10 years' Experience of a Modified Technique). Anaplastology. 2015; 5(155):2161-1173.

14. Snodgrass WT. Does tubularized incised plate hypospadias repair create neourethral strictures? J Urol 1999; 12: 1159-61.

15. Jayanthi VR. The modified Snodgrass hypospadias repair: Reducing the risk of fistula and meatal stenosis. J Urol 2003; 170: 1603-5.

16. Yang SS, Chen SC, Hsieh $\mathrm{CH}$, hen YT (2001) Reparative snodgrass procedure 166: 2342-2345.

17. Duckett JW, Snyder HM $3^{\text {rd }}$. The MAGPI hypospadias repair in 1111 patients. Ann Surg 1991; 213:620-5. 
18. Hastie kJ, Deshpande SS, Moisey CU. Long Term follow-up of the MAGPI operations for distal hypospadias. Br J Urol 1989; 63:320-2.

19. Unluer ES Miroglu C Ozdlier E Ozturk R. Long term follow up results of the MAGPI (metal advancement and granuloplasty) operations in distal hypospadias. lint, Urol Nephrol. 1991; 23:581-7.

20. Atala A. Urethral mobilization and advancement for midshaft to distal hypospadias. J Urol.2002; 168:1738-41; discussion 1741.

21. Darawany HME, Damhogy MEA. Urethral Mobilization as an Alternative Procedure for Distal Hypospadias Repair. J.Urology 2017(104)183-186.

22. Gharieb M. Assessment of meatal mobilization (MEMO) technique for distal penile hypospadias. Ein Shams Journal of Surgery. 2015.

23. Seibold J, Amend B, Alloussi SH, Colleselli D, Todenhoefer T, Gakis G, et al. Meatal mobilization (MEMO) technique for distal hypospadias repair: Technique, results and long term follow up. Central European Journal of Urology. 2010; 63(3).

24. Seibold J, Boehmer A, Merseburger AS, Stenzl A, Sievert KD. The meatal mobilization technique for coronal/ subcoronal hypospadias repair. BJU international. 2007; 100(1):164-7.

25. McGowan AJ Jr, Waterhouse K. Mobalisation of the anterior urethra. Bull NY Acad Med 1964; 40:776-82.

26. Haberlik A, Schmidt B, Uray E, Mayr J. Hypospadias repair using a modification of Beck's operation: follow-up. J Urol 1997; 157: 2308-11.

27. Elemen L, Tugay M: Limited Urethral Mobilisation Technique in Distal Hypospadias Repair with Satisfactory Results Balkan Med J. 2012: 29: 21-25.
28. Koenig JF, Kottwitz $\mathrm{M}$ and McKenna $\mathrm{PH}$ : Urethral Mobalisation for Distal and Mid Shaft Hypospadias with chordee. The journal of Urology. 2013; 190: 15451549.

29. Levent E \& Melih T. Limited urethral mobilization technique in distal hypospadias repair with satisfactory results. Balkan Med J 2012; 29: 21-25.

30. Chakraborty AK, Majumdar SK, Zahid MK, Biswas I, Palit P. Limited urethral mobilization technique in distal hypospadias repair: An overview. Chattagram Maa-O-Shishu Hospital Medical College Journal. 2017; 37-41.

31. Atala A: Urethral mobilization and advancement for mid shaft to distal hypospadias. J Urol. 2002; 168: 1738-1741.

32. Hassan HS, Almetaher HA, Negm M, Elhalaby EA. Urethral mobilization and advancement for distal hypospadias. Annals of Pediatric Surgery. 2015; 11(4): 239-43.

33. Karim S, Aziz A, Rehman A, Parvin S. Limited urethral mobilization (lum) and modified tubularized incised plate (tip) Urethroplasty in distal hypospadias repair; A comparative study. IJCMPR. 2017; 3(8):2232-34.

34. Hamdy $\mathrm{H}$, Awahdi MA, Rasromani KH. Urethral mobilization and meata advancement: A surgical principal in hypospadias repair. Pediatr Surg Int 1999; 15:240-2.

35. Sheikh MA, Latif MA, Ahmad JAM. Hypospadias repair in children: 10-years' experience at Shaik Zayad Hospital Lahore. Professional Med J 2019; 26(7): 10201026.

36. Awad MM. Urethral advancement technique for repair of distal penile hypospadias: A revisit. Indian J Plast Surg 2006; 39:34-38.

\begin{tabular}{|c|c|c|c|}
\hline \multicolumn{4}{|c|}{ AUTHORSHIP AND CONTRIBUTION DECLARATION } \\
\hline Sr. \# & Author(s) Full Name & Contribution to the paper & Author(s) Signature \\
\hline 1 & Shafiq-ur-Rehman & $\begin{array}{l}\text { Introduction/Data collection/ } \\
\text { Result/Materials method. }\end{array}$ & \\
\hline 2 & $\begin{array}{l}\text { Yasir Makki } \\
\text { Fareena Ishtiaq }\end{array}$ & $\begin{array}{l}\text { Discussion, Conclustion, } \\
\text { References, Recommendation. } \\
\text { Discussion, References, Intro. }\end{array}$ & \\
\hline 4 & Waleeja Shamikha & $\begin{array}{l}\text { Discussion, References, } \\
\text { Conclusion. }\end{array}$ & \\
\hline 5 & Nauman Aziz & Biostatistics. & \\
\hline 6 & Saad Fazal & $\begin{array}{l}\text { Intro, Discussion, References, } \\
\text { Recommendation. }\end{array}$ & \\
\hline
\end{tabular}

